\title{
A trans-acting factor required for cAMP- induced gene expression in Dictyostelium is regulated developmentally and induced by cAMP
}

\author{
Annegrethe L. Hjorth, Navin C. Khanna, and Richard A. Firtel ${ }^{1}$ \\ Department of Biology, Center for Molecular Genetics, University of California, San Diego, La Jolla, California 92093 USA
}

\begin{abstract}
We have identified a nuclear activity that binds specifically to a GT-rich sequence or G-box shown previously by use of deletion analysis to be required for cAMP and for developmentally induced expression of the prestalk gene pst-cathepsin (CP2). We show that the insertion of an oligonucleotide that contains the CP2 G-box restores regulated expression whereas the insertion of oligonucleotides that contain mutations in some of the $G$ residues does not. Moreover, the mutant oligonucleotides do not compete for binding of the factor to the wild-type sequence. The activity of the G-box binding factor (GBF) is regulated developmentally with induction of activity occurring at the time of induction of pst-cathepsin expression. In a single-cell culture, GBF activity is inducible by CAMP, and its appearance is inhibited by cycloheximide, which suggests that the factor, or a protein component required for binding of the factor, is directly induced by cAMP and may be the rate-limiting factor required for cAMP induction of pst-cathepsin expression. Models for cAMP induction of prestalk genes are described.
\end{abstract}

[Key Words: Trans-acting factor; DNA-binding protein; Dictyostelium; cAMP; prestalk gene]

Received January 27, 1989; revised version accepted March 30, 1989.

The cellular slime mold Dictyostelium discoideum grows as a single-cell vegetative amoeba. On starvation, a multicellular developmental process is initiated in which $\sim 10^{5}$ individual cells aggregate to form a multicellular organism. Within a few hours, a migrating slug or pseudoplasmodium is formed that contains two major cell types, anterior prestalk cells, which comprise $\sim 20 \%$ of the slug, and posterior prespore cells. A mature fruiting body consisting of $\sim 80 \%$ spores and $20 \%$ stalk cells forms after $\sim 24 \mathrm{hr}$ (Loomis 1975, 1982).

Aggregation is mediated chemotactically by the interaction of CAMP with the chemotactic cAMP cell-surface receptor. This ligand-receptor interaction mediates a number of cellular responses through $G$ proteins (guanine nucleotide-binding proteins) including both chemotaxis, a cAMP relay system that involves the activation of adenylate cyclase, and the induction of expression of a number of genes whose products are required during aggregation (Janssens and van Haastert 1987; Mann and Firtel 1987, 1989; Mann et al. 1987, 1988; Klein et al. 1988; Kumagai et al. 1989; Pupillo et al. 1988). In multicellular aggregates, CAMP induces prestalk and prespore gene expression as well as cytodifferentiation of the respective cell types. The induction of prestalk and prespore genes is also believed to be regu-

${ }^{1}$ Corresponding author. lated via one or more cell-surface cAMP receptors, although the intracellular mechanisms that control the expression of these two classes of genes involve different signal transduction pathways (Mehdy et al. 1984; Mehdy and Firtel 1985; Schaap et al. 1986; Datta et al. 1987; Kumagai et al. 1988; Williams 1988). Aggregation and cell-type specific gene expression can be induced in single-cell culture by cAMP (Williams et al. 1980; Mehdy et al. 1983, 1984; Gomer et al. 1985, 1986a; Mehdy and Firtel 1985; Schaap and van Driel 1985; Haribabu and Dottin 1986; Oyama and Blumberg 1986; Williams et al. 1986; Mann and Firtel 1987). The genes that are induced early during aggregation require a pulsed signal of cAMP every 6 min, whereas the induction of the prestalk and prespore genes requires a higher, continuous level of cAMP to cells that have been starved for 1.5 to $18 \mathrm{hr}$. In response to exogenous cAMP, prestalk mRNAs begin to accumulate within 30-60 min, whereas prespore mRNAs are not de-tectable until $\sim 2$ $\mathrm{hr}$ in a single-cell culture system (Mehdy et al. 1983; Mehdy and Firtel 1985; Schaap and van Driel 1985; Gomer et al. 1986a; Mann and Firtel 1987).

Our group and the Williams laboratory previously analyzed the expression and the cis-acting regulatory regions that control cAMP-inducible and cell-type specific expression of pst-cathepsin (also known as cysteine protease 2 or CP2) (Mehdy et al. 1983; Mehdy and Firtel 
1985; Pears et al. 1985; Gomer et al. 1986a,b; Datta et al. 1986; Datta and Firtel 1987, 1988; Pears and Williams 1987, 1988). Pst-cathepsin expression is induced in developing cells at the time of multicellular aggregate formation and in response to continuous levels of cAMP in single-cell culture. Pst-cathepsin mRNA is localized preferentially in anterior prestalk cells, and its gene product is localized in the anterior portion of the prestalk zone and along the outer edges of a migrating pseudoplasmodium as determined by immunocytology (Datta et al. 1986; Gomer et al. 1986b). We have identified an 80 -bp cis-acting region that lies between -200 and $-280 \mathrm{bp}$ upstream from the cap site and that is necessary for the cell-type specific and cAMP-inducible expression of pst-cathepsin in stable transformants. Internal deletion analysis has identified several regions, all of which have some effect on the quantitative level of expression of the gene during multicellular development and/or induction by cAMP in single-cell culture. Within this region, a tandemly repeated GT-rich element was found to be crucial for proper expression of the gene in either assay. Deletion of both of these elements results in no expression in the single-cell assay in response to cAMP and a >100-fold reduction in expression in cells in multicellular aggregates. The two regions have been designated G-boxes because of the predominance of $G$ residues. There is a single base pair difference between the two G-boxes. The deletion of the downstream $\left\langle 3^{\prime}\right\rangle$ G-box has a more adverse effect on the expression of the gene than the deletion of the upstream (5') G-box. Elements that show homology to the pst-cathepsin G-boxes are found in the $5^{\prime}$ upstream regions of other prestalk cAMP-induced genes (Pears and Williams 1988; Driscoll and Williams 1987; A. Hjorth, J. Williams, and R. Firtel, unpubl.).

To gain a better understanding of the molecular mechanisms that regulate developmental expression of cAMP-inducible prestalk genes in Dictyostelium, we examined a DNA-binding activity that interacts preferentially with the G-boxes (GBF, G-box binding factor). Our results show that the binding activity is regulated developmentally and is inducible by cAMP. In addition, we demonstrate a direct correlation between the kinetics of prestalk gene induction in nuclear run-on experiments, developmental prestalk gene expression, and the regulation of GBF activity.

\section{Results}

\section{G-box is essential for pst-cathepsin expression}

A functional analysis of the structure of the pst-cathepsin (CP2) promoter region is shown in Figure 1A (Datta and Firtel 1988), with an emphasis on the presence of two G-boxes located between nucleotides -233 and -211 . Pst-cathepsin gene constructs with promoter regions that lacked the G-boxes were expressed at levels that were $<1 \%$ of the levels of wild-type constructs (Datta and Firtel 1987, 1988; Pears and Williams 1987, 1988). To gain a better insight to the function of G-boxes and the sequence requirements for pst-cathepsin expression, we cloned oligonucleotides that contained wildtype and mutant G-boxes into a pst-cathepsin promoter construct carrying a 30 -bp deletion (CP2 $\Delta 30$ ) that removed both of the G-boxes (Pears and Williams 1987). These constructs were transformed into Dictyostelium cells, and the effects of the wild-type G-box oligonucleotides and of those that contained point mutations were examined in stable transformants. The recorder gene was a pst-cathepsin minigene that produced an mRNA that was 750 nucleotides smaller than the endogenous mRNA. This allowed us easily to distinguish the minigene transcripts of the transformant from the endogenous mRNA and to compare the two internally (Pears and Williams 1987).

Two different types of oligonucleotides were used in these studies, a 43-mer and a 36-mer (Fig. 1A), both of which included the two CP2 G-boxes. The two oligonucleotides have been designated as CP2 43-mer and CP2 36-mer to refer to their derivation from the pst-cathepsin-cysteine protease 2 gene and to distinguish them from related G-box oligonucleotides from the cysteine protease 1 (CP1) gene (see Pears and Williams 1988). In addition to the G-boxes present in the 36-mer, the 43-mer oligonucleotide included a short alternating TATA sequence located downstream of the G-boxes in the pst-cathepsin promoter. This sequence was still present in $\Delta 30$. Independent in vitro DNA-protein studies have indicated that this additional sequence element most probably increases the affinity of the transacting factor we identified for the G-boxes (N. Khanna, A. Hjorth, and R. Firtel, unpubl.). The CP2 36-mer contains a few more nucleotides upstream from the G-box that also are found in the CP2 promoter but that are not found in the CP2 43-mer. The point mutations that we investigated in the 43-mer oligonucleotide were localized solely in the downstream G-box whereas the 36mer mutant oligonucleotide carried a change in both of the G-boxes. The $\mathrm{G}$ residues mutated in the 36 -mer were required for binding as determined by dimethyl sulfate (DMS) methylation-interference studies (see below).

Figure $1 \mathrm{~B}$ shows the expression of the CP2 oligonucleotide constructs in tipped multicellular aggregates, the developmental stage at which pst-cathepsin is expressed maximally. As can be seen, the minigene $\Delta 30$ was not expressed detectably in stable transformants, however, the addition of a single copy of either of the G-box oligonucleotides yielded a significant level of expression relative to the wild-type with an undeleted promoter. Insertion of tandem copies of either oligonucleotide resulted in an even higher level of gene expression although it was still lower than that seen for the minigene construct that carried a wild-type upstream sequence of the pst-cathepsin promoter. In contrast, neither mutant oligonucleotide conferred a significant increase in the level of expression. In all of these constructs, the oligonucleotide was inserted in an orientation that corresponded to the wild-type sequence arrangement of the G-boxes.

\section{Identification of putative trans-acting factors that interact with the G-box}

To examine nuclear proteins that interact with this region, probes that contained one or two cloned copies of 
the CP2 43-mer were used in gel mobility shift assays with nuclear extracts isolated from tipped aggregates that had been developing for $15 \mathrm{hr}$, the time of maximal pst-cathepsin transcription (see Materials and methods). Crude nuclear extracts contain substantial amounts of nonspecific DNA-binding activity, therefore, specific banding on gel shifts could only be obtained when poly[d(I-C)] was used as a nonspecific competitor (data not shown). Precolumns as well as heat treatment under various conditions were attempted to eliminate the interference of nonspecific binding activity. Our results indicated that a brief treatment of $2 \mathrm{~min}$ at $80^{\circ} \mathrm{C}$ allowed analysis of a G-box-specific binding activity (N. Khanna, A. Hjorth, and R. Firtel, in prep.).

Specificity of DNA complex formation was determined by the ability of unlabeled probe DNA to compete for binding activity in comparison to other nonspe- cific DNAs. Analysis of the specificity of the G-box binding activity is shown in Figure 2A. By use of the probe 413 , which contains one cloned copy of the CP2 43-mer G-box oligonucleotide (see Materials and methods), we observed a single band in the presence of poly[d(I-C)]. Competition experiments were performed with a number of specific and nonspecific DNAs including: unlabeled 413 probe; 431 fragment that contained two tandemly cloned CP2 43-mers; self-ligated 43-mer; self-ligated CP2 36-mer; self-ligated mutant forms of 43-mer and 36-mer, respectively; fragment 452 [a 140-bp region that contained the upstream sequences of pst-cathepsin from -313 to -176 and included the two G-boxes (see Fig. 1A)]; clone 455 (an 81-bp region that was a 59-bp $3^{\prime}$ deletion of clone 452 and that carried sequences from -313 to -233 but did not contain the two G-boxes); ligated oligonucleotide that contained the
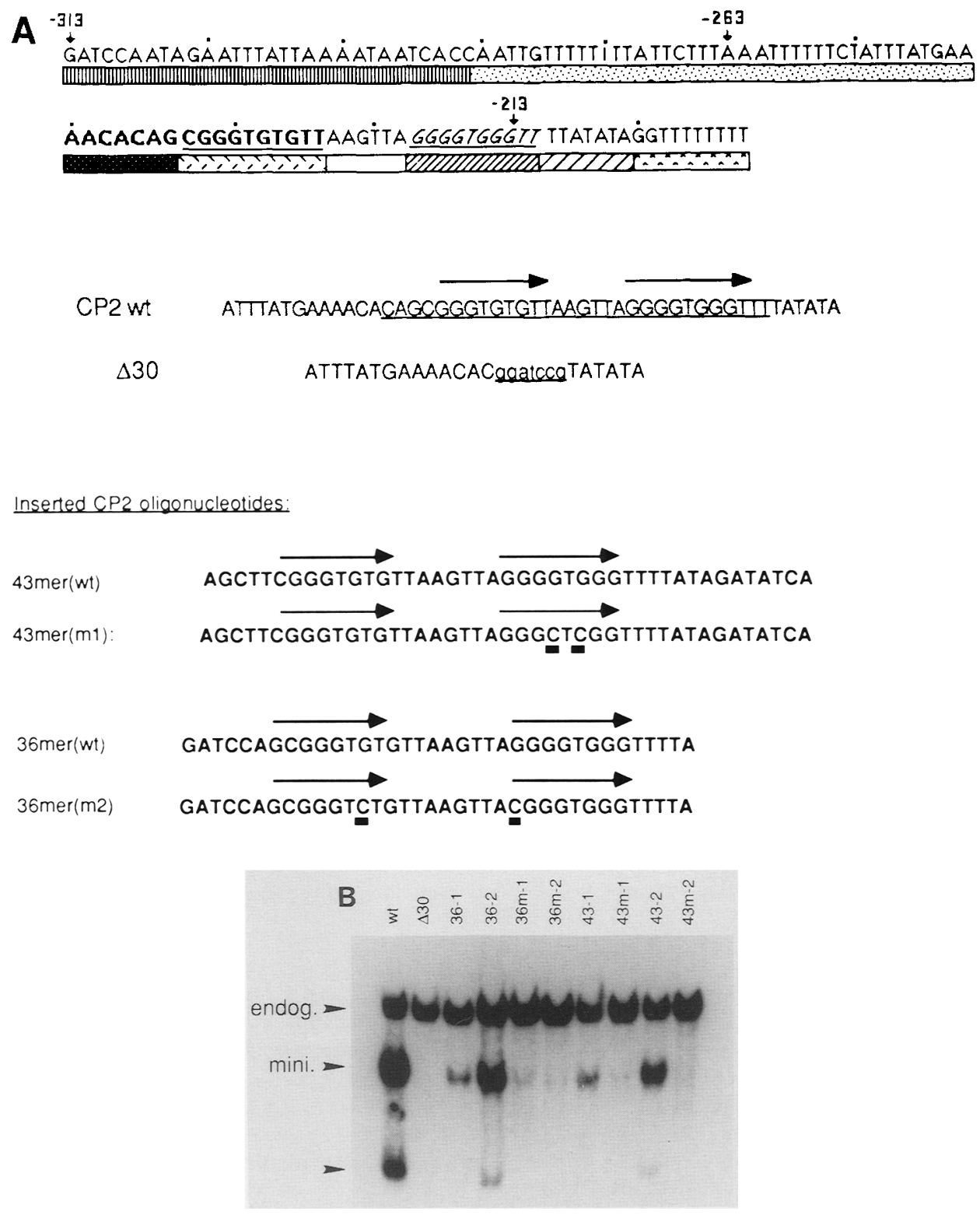

Figure 1. (See following page for legend.) 
Hjorth et al.

cAMP regulatory element (CRE) from mammalian cells; a number of synthetic polynucleotides; sheared Escherichia coli DNA; a HinfI digest of pBR322 DNA; a selfligated 22-mer oligonucleotide from a relatively GC-rich upstream region of the Discoidin I- $\alpha$ gene /region I, Poole and Firtel 1984); a 152-bp primarily AT-rich fragment that contained the 5 -upstream regulatory region of the Actin 6 gene including an identified fairly G-rich control element (sequences -255 to -104 ; Nellen et al. 1986); and a 287-bp fragment that extended from -154 to +126 relative to the Dictyostelium ras gene cap site (Reymond et al. 1984, 1985; R.K. Esch and R. Firtel, unpubl.). The ligated 43-mer as well as the cloned monomer (413) and dimer (431) CP2 43-mer oligonucleotides competed very well, the dimer and ligated oligonucleotides being much better than the monomer form. Figure $2 \mathrm{~B}$ shows that the CP2 36-mer also competed although a quantitative analysis indicated that it did not compete as well as the CP2 43-mer (data not shown).

Clone 452 competed well (the mass excess was 50 -fold and the molar excess was 10 -fold); however, a deletion that lacked the G-box (e.g., clone 455), showed no competition. We also tested a series of other $5^{\prime}$ and $3^{\prime}$ deletions of clone 452 . All $5^{\prime}$ or $3^{\prime}$ deletions that extended up to but did not include the G-boxes competed for binding, whereas $5^{\prime}$ or $3^{\prime}$ deletions that extended through the G-box did not compete (data not shown), indicating that the GT-rich region is essential for the binding. All of the other DNAs we tested did not compete at a 50-fold mass excess except for the $5^{\prime}$-upstream region of the Dictyos. telium ras gene. Interestingly, this gene was shown to be induced by cAMP and to be expressed preferentially in prestalk cells (Reymond et al. 1984, 1985) and to have a direct repeat with some homology to the upstream pstcathepsin G-box. Whether or not this particular region was responsible for the competition is not known. Higher levels of $E$. coli DNA and pBR322 DNA showed some competition.

In addition, competitions were done with the self-ligated CP2 36-mer and 43-mer mutant oligonucleotides. Neither of these oligonucleotides competed for binding [see Fig. 2B for CP2 36-mer and Fig. 5B (below) for CP2 43-mer]. The occurrence of competition by the wild-type oligonucleotides and the lack of competition by the mutant forms was as would be expected if the factor (GBF) that binds to the CP2 G-box is associated with developmental activation of the pst-cathepsin gene in vivo.

We used methylation-interference studies to examine the effects of methylation of purine residues on DNA binding. End-labeled probe 413 DNA was treated with DMS, mixed with extract, and the complexed DNA was separated from free DNA on the basis of mobility in native gels. The two forms of DNA probe were purified, cleaved at the methylated purines, and sized on sequencing gels. The uncomplexed DNA band includes molecules that have been methylated on $G$ residues that must remain unmethylated for binding of the factor to occur. As a consequence, the complexed DNA band is depleted of these methylated species. $G$ residues that appear as protected in the cleaved DNA ladder are considered essential for complex formation. Figure 3 shows that two $\mathrm{G}$ residues localized within both of the G-boxes were strongly protected, which indicates that methylation of these residues blocks binding of the factor. In addition, several other $\mathrm{G}$ residues may show partial protection. The two mutations present in the mutant 36-

Figure 1. Function of G-box in the control of pst-cathepsin expression. (A) A schematic cartoon of the sequence and structure of the upstream regulatory region of pst-cathepsin. The region between -203 and -283 is required for expression of the pst-cathepsin gene (Datta and Firtel 1987, 1988; Pears and Williams 1987). The different regions refer to functional domains as determined by deletion analysis (see Datta and Firtel 1988). Deletion of the region between -313 and -283 had no effect on expression. The regions that contain the G-boxes are shown by an underlining of the sequence. Deletion of either G-box resulted in a substantial reduction in the level of expression. Deletion of both G-boxes resulted in no detectable expression. Deletions of other regions also resulted in quantitative increases or decreases in expression, but the changes were small compared to effects seen with deletion of the G-boxes (Datta and Firtel 1988|. Sequence labeled CP2wt accentuates the G-boxes and the region around the G-boxes in the pst-cathepsin regulatory region. Below is shown $\Delta 30$, which contains a 30-bp deletion centered around the G-boxes (Pears and Williams 1987) and an inserted BamHI linker. The $C$ residues immediately $5^{\prime}$ to the linker in $\Delta 30$ were derived from the BamHI linker but replaced the $C$ residue present in the original sequence. Also shown below are the wild-type and mutant oligonucleotides (43-mer and 36-mer) that were inserted into the CP2 $\Delta 30$ transformation vector and used as competitors in the DNA binding analysis. Nucleotides that have been changed in the mutants are underlined. Note that the 36-mer is flanked by GATC sticky ends and the 43-mer is flanked by HindIII sites. An EcoRV site was also placed internal to the downstream HindIII site. This site is similar to the endogenous sequence and allowed the determination of the orientation of the oligonucleotide in a different set of experiments. $(B)$ Northern analysis of pst-cathepsin gene expression in transformants that carried oligonucleotide constructs. Total cellular RNA was prepared from transformants that developed into multicellular-tipped aggregates. The larger mRNA represents the endogenous pst-cathepsin (CP2) transcript and the smaller one represents mRNA from the transformed gene. A small species (indicated by unlabeled arrow) came from the transformed gene and was probably the result of early transcriptional termination because of the internal deletion in the CP2 coding sequence. When this promoter was linked to another recorder gene no smaller species was observed (Datta and Firtel 1987, 1988). wt, represents $\sim 900 \mathrm{bp}$ of wild-type upstream pst-cathepsin (CP2) sequence; $\Delta 30$, a construct that carried a 30 -bp deletion that removed both of the regulatory G-box elements; $36-1$, a construct that had one copy of the CP2 (G-box) 36-mer inserted into the $\Delta 30$ vector; $36-2$, a construct that had two copies of the $36-$ mer inserted in tandem. $36 \mathrm{~m}-1$ and $36 \mathrm{~m}-2$, are constructs that carried one and two copies of the mutant 36-mer oligonucleotide, respectively. 43-1, 43-2, $43 \mathrm{~m}-1$, and $43 \mathrm{~m}-2$ refer, in analogy, to constructs that carried one or two copies of the wild-type 43-mer oligonucleotide and one and two copies of the 43-mer mutant oligonucleotide. The probe used in this analysis included sequence from the $5^{\prime}$ half of the pst-cathepsin (CP2) gene (see Materials and methods). (Note: insertion of the CP2 36-mer gave a higher level of expression than the CP2 43-mer in the $\Delta 30$ construct. Previously, we have shown that spacing between the G-boxes and between other cis-acting elements in this region is essential for maximal levels of expression. The higher level of expression conferred by the CP2 36-mer compared to the CP2 43-mer may be a result of such a spacing effect.) 


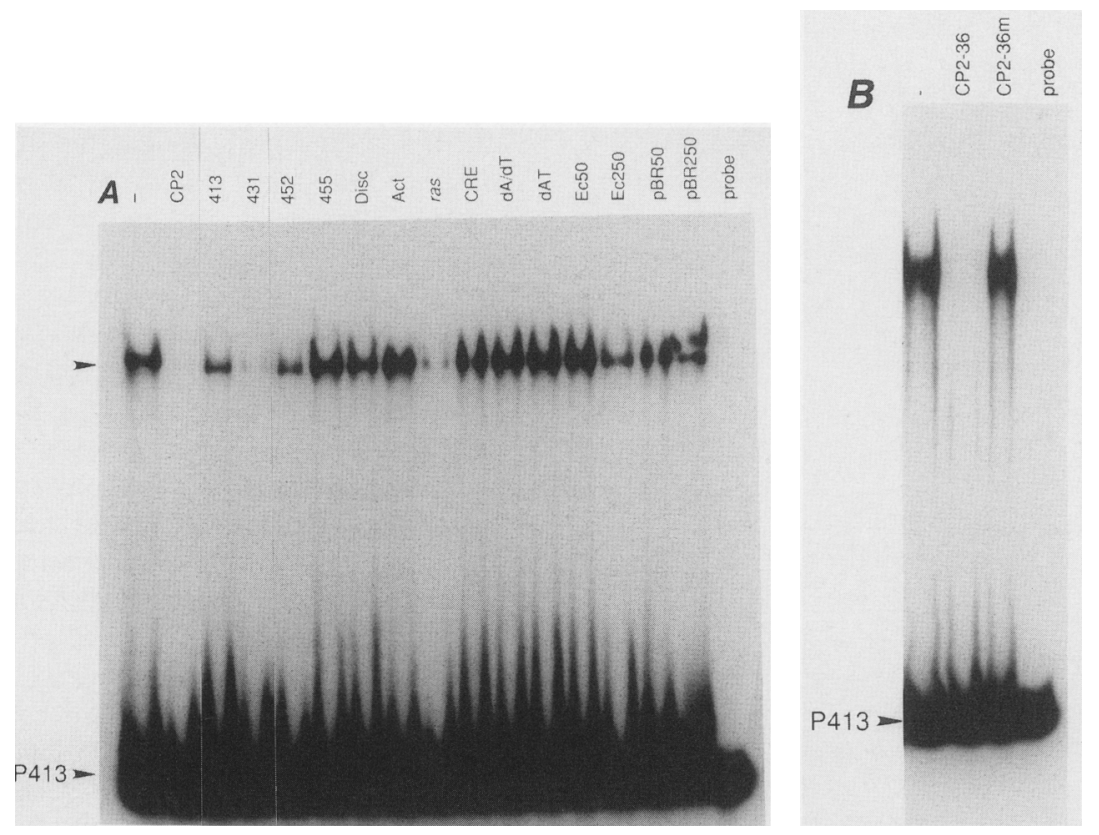

Figure 2. Gel mobility shift assay of G-box binding factor. Extracts were prepared from tipped aggregates, $\sim 15 \mathrm{hr}$ in development, the time period of maximal pst-cathepsin expression, and assayed for binding activity to cloned CP2 G-box oligonucleotide 413, which was a 72-bp PstI-Asp718 fragment that included one cloned copy of the CP2 43-mer G-box oligonucleotide surrounded by polylinker sequences from pSP72 and pUC18. All reactions were done in the presence of a 500-fold mass excess of poly[d(I-C)]. (A) The first lane $(-)$ contains no additional competitor in addition to a 500-fold excess of poly[d(I-C)]. All other lanes contain either specific or nonspecific competitor at 50-fold mass excess: (Lane CP2) ligated CP2, 43-mer oligonucleotide; (lane 413) unlabeled probe; (lane 431), cloned dimer of the CP2 oligonucleotide; competitors 452, 455, ras, and Act (CP2 Actin 6), described in the text; (lane Disc) 22-mer oligonucleotide

\section{(5'-GATCCTTGGGAAATTTCACTTA 3'-GAACCCTTTAAAGTGAATCATG)}

from the upstream regulatory region of Discoidin I- $\alpha$ (Poole and Firtel 1984); (lane CRE) ligated oligonucleotide containing the cAMP regulatory element from mammalian cells

\section{(5'-GATCCGGCGCCTCCTTGGCTGACGTCAGAGAG 3'-GCCGCGGAGGAACCGACTGCAGTCTCTCCTAG)}

$d A T$ and $d A / d T$, double-stranded homo or alternating deoxy-polynucleotides; (lanes $E c 50$ and $E c 250$ ) 50- and 250-fold mass excess, respectively, of randomly sheared E. coli DNA; (lanes pBR50 and pBR250) 50- and 250-fold, respectively, of pBR322 DNA; (lane probe) the probe in the absence of extract; and P413 at the bottom of the gel, free probe. (Note: All lanes are from the same gel. Some lanes not related to these experiments were removed.) (B) Competition assay with ligated CP2 36-mer (CP2-36) and mutant CP2 36-mer (CP2-36m). Separate but analogous competition experiment with additional competitors. The upper arrow points to the band of the protein-probe complex. The lower arrow, labeled P413, indicates unbound probe.

mer oligonucleotide specifically affected the two guanine residues that were strongly protected in the methylation-interference analysis. Mutations of both of these residues were demonstrated clearly to have reduced significantly the binding affinity of GBF for the regulatory element (see Fig. 2), and such mutations did not complement promoter activity in CP2 230 (see Fig. 1). Whether mutation of just one of the $G$ residues would suffice to prevent complex formation, however, is not known presently.

\section{Developmental regulation and induction of $G B F$ activity by cAMP}

We examined the developmental regulation of G-box binding activity. Equal amounts of nuclear extracts prepared from Dictyostelium cells at various develop- mental stages were analyzed by the gel shift assay by use of both 413 (monomer) and 431 (dimer) CP2 43-mer oligonucleotide probes. As seen in Figure 4, nuclear extracts from 0- and 5-hr development showed very low levels of specific binding activity. The activity levels increased substantially at $10 \mathrm{hr}$, the time of loose aggregate formation when prestalk gene expression is first induced. Binding activity remained fairly constant at 15 and $20 \mathrm{hr}$. The binding activity at all time points exhibited the same G-box specificity as the activity examined in Figure 2 (see Fig. 4; data not shown).

The above results indicate that the GBF nuclear factor that binds specifically to the CP2 G-boxes is regulated developmentally. To understand further the regulation of binding activity during development, we examined the effect of cAMP on the level of binding activity by use of a single-cell culture system, and tested whether de novo protein synthesis is required for the increase in 
Hjorth et al.

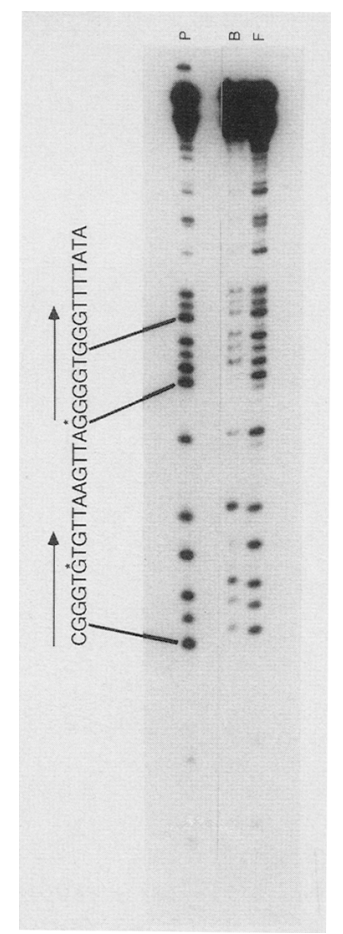

Figure 3. Methylation-interference analysis of G-box factor binding. The effect on complex formation after partial methylation of guanine residues. An SphI-Asp718 fragment of the cloned CP2 43-mer oligonucleotide labeled at the Asp 718 site was used as a probe (see Materials and methods). The bands representing $G$ residues are aligned with the actual sequence of the G-boxes present in the probe. $(F)$ Partially methylated DNA isolated in an uncomplexed form; $(B)$ partially methylated DNA that was isolated from protein complexes; $(P)$ fully methylated and cleaved probe DNA. $B$ had fewer counts than lanes $F$ or $P$. The G-box elements are indicated by arrows, and the asterisk $(*)$ identifies the most strongly protected guanine residues seen in the complexed form of the methylated probe. The depurination cleavage (see Materials and methods) was done with piperidine which cleaves preferentially at methylated G residues. (Note: All lanes are from the same gel. Some lanes not related to these experiments were removed.)

binding activity. Figure 5A outlines the protocol used in the experiment. Vegetative cells were washed and resuspended in phosphate buffer at $10^{7}$ cells per milliliter and shaken at $110 \mathrm{rpm}$. At $1.5 \mathrm{hr}$, the cells were split into several aliquots. cAMP was added to one aliquot while another aliquot continued to be shaken in the absence of cAMP. Cells were harvested at $4.5 \mathrm{hr}$. Under these conditions, no pst-cathepsin mRNA was seen in cells cultured in the absence of added cAMP, and when cAMP was added at $1.5 \mathrm{hr}$, a high level of pst-cathepsin mRNA accumulated by $4.5 \mathrm{hr}$ (data not shown; see Mehdy et al. 1983; Mehdy and Firtel 1985). To examine a requirement for protein synthesis, an aliquot of the cell culture received cycloheximide from the start of the experiment $\left(t_{0}\right)$ and cAMP at $1.5 \mathrm{hr}$, and another aliquot was given cycloheximide at $60 \mathrm{~min}$ and cAMP at $1.5 \mathrm{hr}$. Under neither of these conditions was pst-cathepsin mRNA observed (data not shown).
Nuclear extracts were prepared from cell cultures in the experiment described above and examined for sequence-specific G-box binding activity. The results are shown in Figure 5B. As can be seen, the level of binding activity was very low in cells cultured without added cAMP. This level was approximately the same as that seen in the 0- and 5-hr samples of the developmental time course (see Fig. 4). A much higher level of binding activity was induced by cAMP. However, when cycloheximide was added either $60 \mathrm{~min}$ prior to or at the same time as CAMP, there was, in both instances, only a minor, but measurable, increase in the level of binding activity. These results indicate that the GBF activity is inducible by CAMP and that the vast majority of this increase requires de novo protein synthesis. There is no change in binding activity when cAMP is added directly to extracts as would be expected if cAMP mediates the activation of pst-cathepsin gene expression via a cellsurface cAMP receptor (data not shown).

To test and correlate the relationship of the increase in binding activity and pst-cathepsin expression in greater detail, we examined the kinetics of cAMP induction of pst-cathepsin transcription by use of nuclear runon experiments. The results of these experiments are shown in Figure 6. Nuclei from untreated cells showed no detectable pst-cathepsin gene transcription above background (see Materials and methods). In response to cAMP, transcription was observed within $10 \mathrm{~min}$; however, a maximal level of transcription was not reached until $\sim 70 \mathrm{~min}$. These kinetics indicate that an intermediate, rate-limiting, step is required to induce a full level of pst-cathepsin transcription. Therefore, we examined the possibility of requirements for prior and concomitant protein synthesis. Cycloheximide was added either $15 \mathrm{~min}$ before or $20 \mathrm{~min}$ after the addition of cAMP. Addition of cycloheximide prior to cAMP totally blocked activation of pst-cathepsin transcription. When cycloheximide was added at $20 \mathrm{~min}$, the level of pst-cathepsin transcription decreased slowly, which indicated that concomitant protein synthesis was indeed required for continued transcription.

\section{Discussion}

Pst-cathepsin or cysteine protease 2 is expressed preferentially in the anterior region of the prestalk zone in migrating pseudoplasmodia. During multicellular development, pst-cathepsin mRNA is expressed first at the time of the formation of the multicellular aggregate. In single-cell culture systems, the gene is induced in response to moderate concentrations of exogenously added cAMP (Mehdy et al. 1983; Mehdy and Firtel 1985; Pears and Williams 1985). This induction occurs in mutants that are not capable of activating adenylate cyclase in response to an extracellular cAMP signal or in wild-type cells in which adenylate cyclase activation is blocked with caffeine (Gomer et al. 1986a; Schaap et al. 1986; Kumagai et al. 1988; S. Mann and R. Firtel, unpubl.). These and other experiments indicate that induction of 

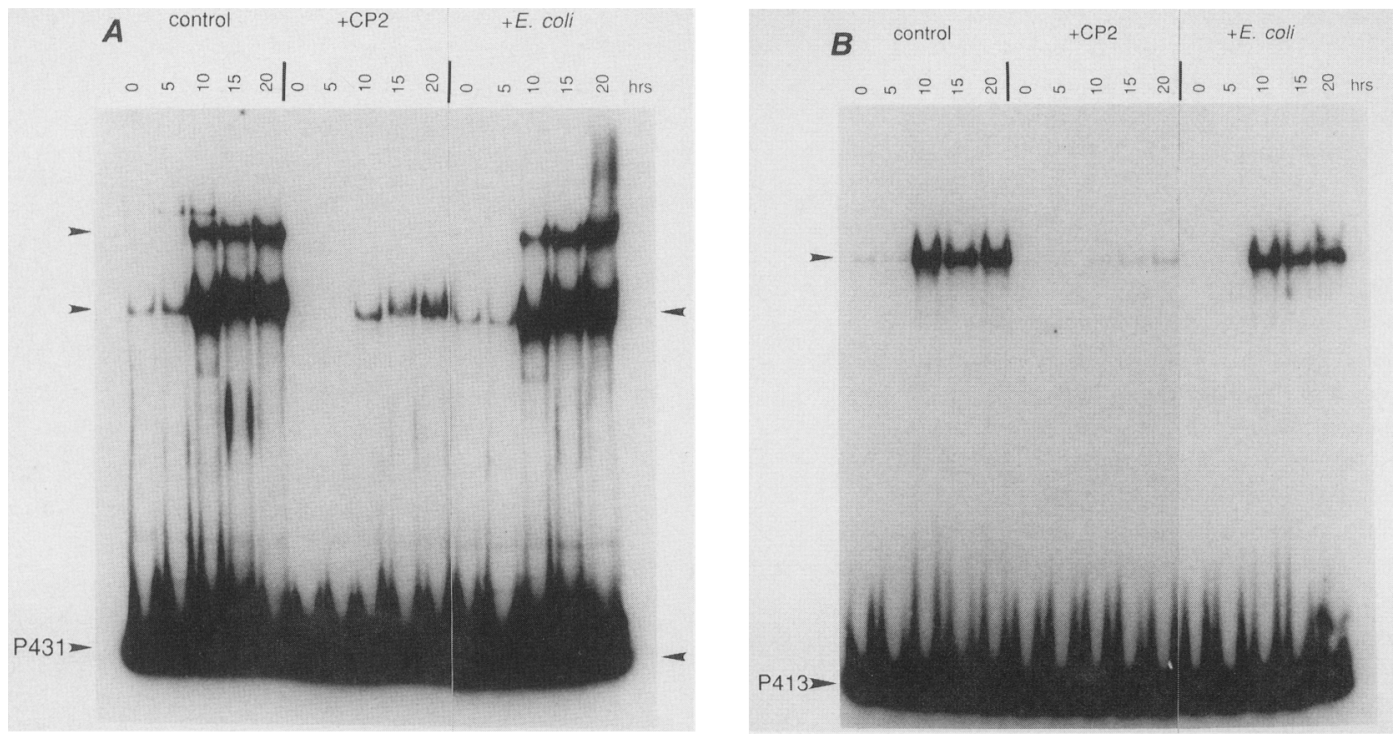

Figure 4. Developmental time course of G-box binding activity. (Lane 0 ) Extracts made from vegetative cells. (Lanes 5, 10, 15, and 20) Extracts made from 5, 10, 15, and $20 \mathrm{hr}$ of development. Loose aggregates were formed at $10 \mathrm{hr}$, and tipped aggregates and slugs at 15 $\mathrm{hr}$, and early fruiting bodies at $20 \mathrm{hr}$. For these experiments, probe 431, which carried a cloned tandem repeat of the CP2 43-mer wild-type oligonucleotide $(A)$ or probe 413 , which contained a single copy of this oligonucleotide $(B)$ were used. The 431 probe was used because it better quantitates the relative levels of G-box binding activity. Upper arrows indicate the bands that presumably represent binding to either one of the two (lower band) or both G-box oligonucleotides. Also shown are competitions with a 30-fold excess of CP2-ligated 43-mer oligonucleotide or 30-fold mass excess of random sheared E. coli DNA. (Note: All lanes are from the same gel. Some lanes not related to these experiments were removed.)

\section{A}

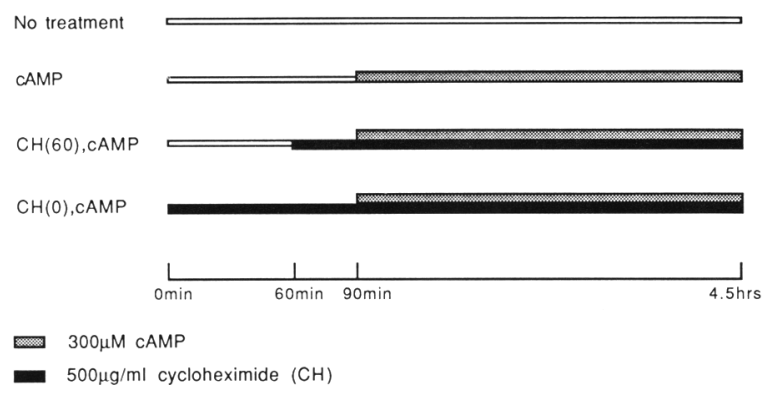

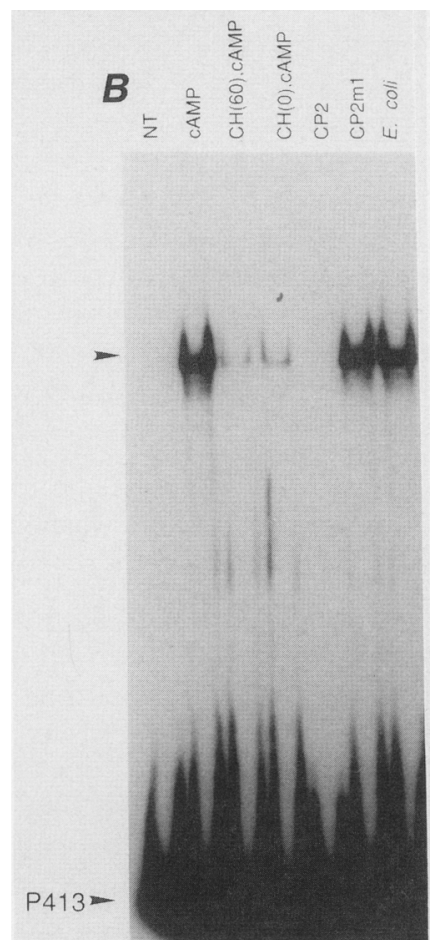

Figure 5. Induction of G-box binding factor by cAMP. $(A)$ Schematic diagram of the experimental design. $(B)$ Gel mobility shift of nuclear extracts made from cells that were isolated according to the experimental design shown above. (Lane NT) Extract from $4.5 \mathrm{hr}$ in the absence of treatment. (Lane $c A M P$ ) Extract from cells that were given cAMP at $1.5 \mathrm{hr}$. (Lanes $C H(60), c A M P$ and $C H(0), c A M P$ ). Extracts from cells given cycloheximide either at $60 \mathrm{~min}$ or $0 \mathrm{hr}$ and cAMP at $1.5 \mathrm{hr}$, respectively. (Lane CP2) Competition of the + cAMP assay with a 30-fold mass excess of ligated CP2 43-mer wild-type oligonucleotide. CP2m1 refers to the mutant CP2 43-mer. 
Hjorth et al.

Figure 6. Kinetics of induction of pst-cathepsin transcription. Rate of transcription was measured by use of nuclear run-on assays and assayed by hybridization of the in vitro-synthesized RNA to filters that carried pst-cathepsin cDNA, pSP73 vector DNA, and IG7 cDNA. [IG7 is a gene expressed at a uniform level throughout development (Early and Williams 1988)). The level of transcription was calculated from the maximal level of transcription observed during the developmental time course (later time points). To normalize internally possible differences in nuclear yields from different time points, samples were normalized to hybridization to IG7. The level of IG7 hybridization varied $<20 \%$ from experiment to experiment. The filters were autoradiographed and densitometer tracings were done using an LKB laser densitometer. Background hybridization to pSP73 DNA $1<2 \%$ of hybridization from the 70-min + cAMP time point) was subtracted from all samples. $(\bullet, \triangle)$ cAMP at $t_{0} ;(\diamond)$ cycloheximide at $t=-15$, cAMP at $t_{0}$; () cAMP at $t_{0}$, cycloheximide at $t=20$.

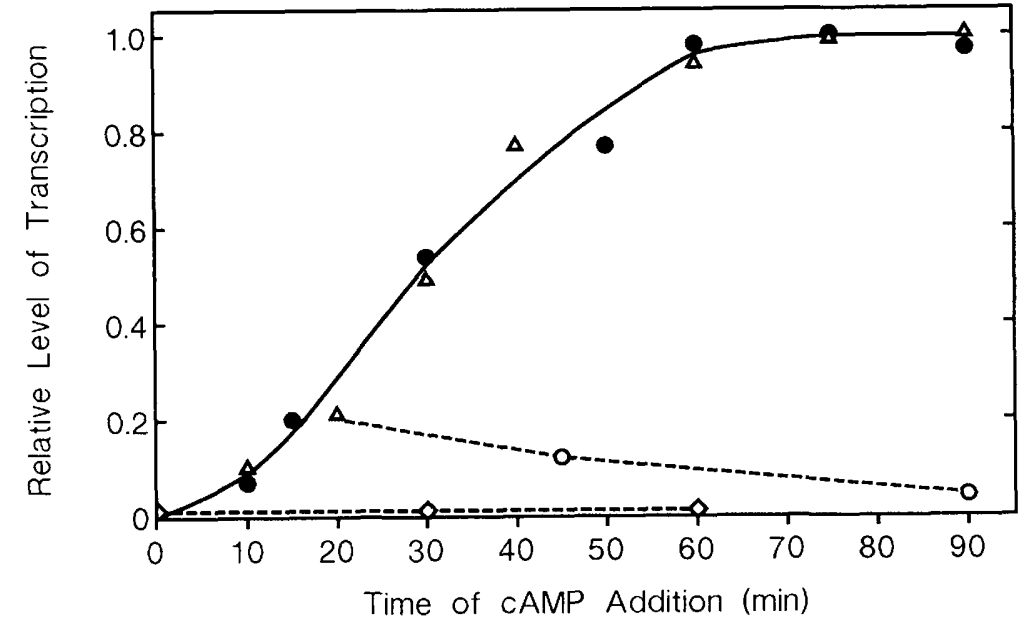

markably different DNA sequences (Johnson et al. 1987; Pfeifer et al. 1987; Landshulz et al. 1988).

The results of gel shift and methylation-interference analyses indicate that specificity of DNA binding by the trans-acting factor involves both of the CP2 G-boxes. First, only a single band was seen in the gel shift when a 43-mer monomer, which has both the $5^{\prime}$ and 3' G-boxes, was used as a probe (see Fig. 2). Titration of the probe with increasing amounts of extract did not alter this binding pattern, nor was a cooperative binding mechanism implicated (data not shown). In contrast, a 43-mer dimer probe showed one major band at low extract concentrations and two major bands at increasing extract concentrations, which indicated two binding sites, one for each monomer. This argument was substantiated by the observation that a self-ligated oligonucleotide that contained only the downstream G-box competed poorly for complex formation (data not shown) and furthermore, by the lack of competition that was seen with the 43-mer mutant oligonucleotide. This oligonucleotide carried an intact 5' G-box and a mutated 3' G-box.

An important question concerns whether the DNA binding activity we observed in vitro was involved in the control of the expression of this gene in vivo. One observation supporting this idea involved the developmental kinetics of DNA-binding activity in relationship to the developmental kinetics of pst-cathepsin expression. Second, we have shown a direct correlation between the ability of CP2 36-mer and 43-mer wild-type and mutant oligonucleotides to activate pst-cathepsin transcription when inserted into the CP $2 \Delta 30$ construct and the ability of these oligonucleotides to compete for binding of the factor to the labeled probe. Oligonucleotides that activated CP2 $\triangle 30$ expression in vivo compete for binding in vitro, and mutant oligonucleotides that did not activate expression in vivo do not compete in vitro. Methylation-interference studies showed that methylation of two of the $G$ residues blocked binding. When both of 
these residues were changed [oligo CP2 36-mer (m2) (see Fig. 1), the oligo no longer complemented the CP2 $\Delta 30$ promoter construct nor did it compete for binding of GBF. In another G-box mutation, we changed two other $G$ residues that did not show strong methylation interference in in vitro binding studies. It is possible that none of these other $\mathrm{G}$ residues is individually essential for binding; however, changes in more than one reduced the affinity for GBF to such an extent that the oligonucleotide did not bind in vitro (see Figure 5B) nor did it function in vivo (see Fig. 1).

Our results also shed light on the mechanisms that control the mode of cAMP induction of pst-cathepsin. In mammalian cells, it is believed that cAMP induction of gene expression is mediated through cAMP-dependent protein kinase A, possibly by a direct phosphorylation of the trans-acting factor that interacts with the CRE (see Yamamoto et al. 1988). In Dictyostelium, cAMP induction of prestalk and several other classes of genes is believed to be regulated through a signal-transduction process that involves the cell-surface receptor-specific $G$ proteins, and possibly the activation of phospholipase $\mathrm{C}$ (see introductory section and Mann et al. 1988). Because this is a developmentally regulated event, one might expect either part of the signal-transduction system, an enzyme or factor located downstream from the effector protein that is activated by the receptor and G protein, or possibly one or more trans-acting factors to be regulated developmentally. The cAMP-induced signal-transduction system could activate one or more of these factors, possibly by a post-translational modification or by the activation of the factor's synthesis. Our data support that either the trans-acting DNA-binding protein identified in our analysis $(G B F)$, or a protein that modifies the binding activity in response to CAMP, is regulated developmentally. First, we showed that the DNA-binding activity is regulated developmentally and is inducible by cAMP. This induction is sensitive to cycloheximide, which indicates a requirement for de novo protein synthesis. These data are consistent with the nuclear run-on results that demonstrated a requirement of $\sim 70 \mathrm{~min}$ for maximum transcription of the pst-cathepsin gene in response to cAMP and that this induction is sensitive to cycloheximide. The $70-\mathrm{min}$ period required for maximum transcription is consistent with the synthesis and accumulation of a limiting protein. The sensitivity of pst-cathepsin transcription to cycloheximide $20 \mathrm{~min}$ after addition of cAMP indicates that one or more of the protein factors involved in this process has a rapid turnover. We attempted to assay GBF activity in whole-cell extracts at different developmental stages as well as before and after cAMP induction to determine if activity is initially sequestered in the cytoplasm. However, we could not obtain specific inding because of interfering proteins in whole-cell extracts. Therefore, we cannot eliminate absolutely the possibility of a protein-synthesis-dependent transfer of the factor from the cytoplasm to the nucleus. With the continued sensitivity of transcription to cycloheximide, we do not feel that this is the mechanism that functions in these cells.
Possible models for the processes involved in activation of pst-cathepsin expression are presented in Figure 7. In the first model, cAMP activation of the receptor results in a modification of a trans-acting factor that increases its specificity for the G-box regulatory element (GBRE), thereby directly inducing pst-cathepsin and other prestalk genes. As described above, both the kinetics of the induction of pst-cathepsin transcription and the cycloheximide experiments are inconsistent with this model. In model IIA, cAMP activation of a constitutive factor results in the activation of the gene that encodes GBF. The factor is synthesized and interacts subsequently with the pst-cathepsin and other cAMP-inducible prestalk gene promoters thereby inducing transcription of these genes. The kinetics of induction, the cycloheximide experiments, and the developmental kinetics are consistent with this model. Model IIB is also consistent with our results. In this model, there is a low level of constitutive expression of the GBF throughout early development. This is seen as a low level of specific GBF activity found in vegetative cells and cells that have developed for $5 \mathrm{hr}$. In response to cAMP, this low activity of the factor is increased, possibly through a phosphorylation or other post-translational modification. The factor now interacts with a cisacting region of the gene that encodes the factor, which results in increased transcription of the gene and the production of more GBF. At a higher level of factor, stable complexes are formed with cis-acting G-boxes of the prestalk-specific genes. Possible differences in the binding constants of the factor for the upstream regulatory regions of these different subsets of genes as well as of other trans-acting proteins would allow the factor to differentiate between the gene for the factor and for the downstream genes when the factor is present at limiting levels.

In support of this model is the observation that cAMP causes a two- to threefold increase in binding activity following treatment with cycloheximide, which indicates that there is some increase in binding activity in the absence of protein synthesis. This could be the result of a change in the binding activity of an already present factor in response to activation of the receptor. Biologically, this last model is intriguing, because it would allow the organism to regulate carefully the expression of a large number of prestalk-specific genes and to respond to changing physiological conditions as the aggregate of cells differentiates in nature. In metazoan cells, cAMP modulates the expression of a large number of genes, possibly through the phosphorylation of the CRE binding activity. In many cases, these genes are expressed at a low level in the absence of cAMP, and the activation of adenylate cyclase via a receptor allows the genes to respond quantitatively by increasing their expression (Yamamoto et al. 1988). In Dictyostelium, however, cAMP acts as a morphogen that controls the differentiation of various classes of cells. Moreover, cAMP mediates these events as an extracellular factor that interacts with cell-surface receptors. The cells need to be able to respond to cAMP in a cell-type specific manner that results in major changes in the developmental state 
Hjorth et al.

1:

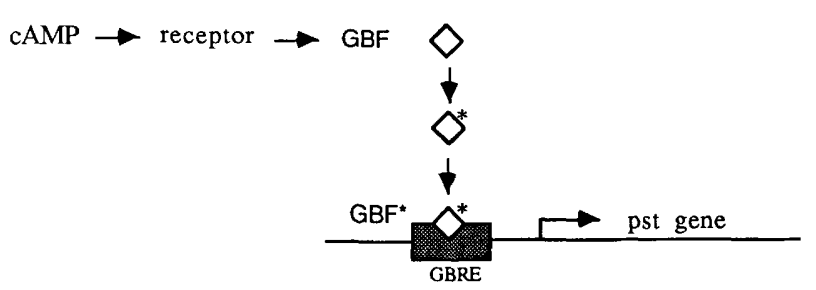

11A:

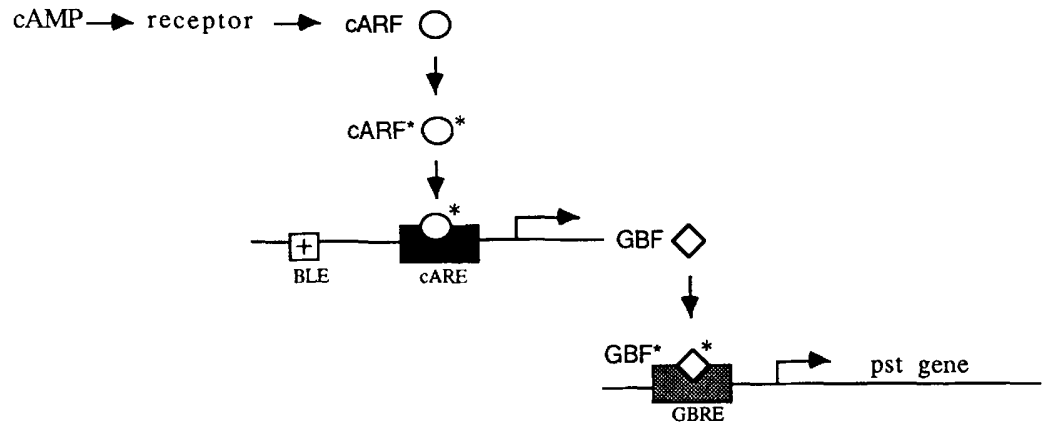

II B:

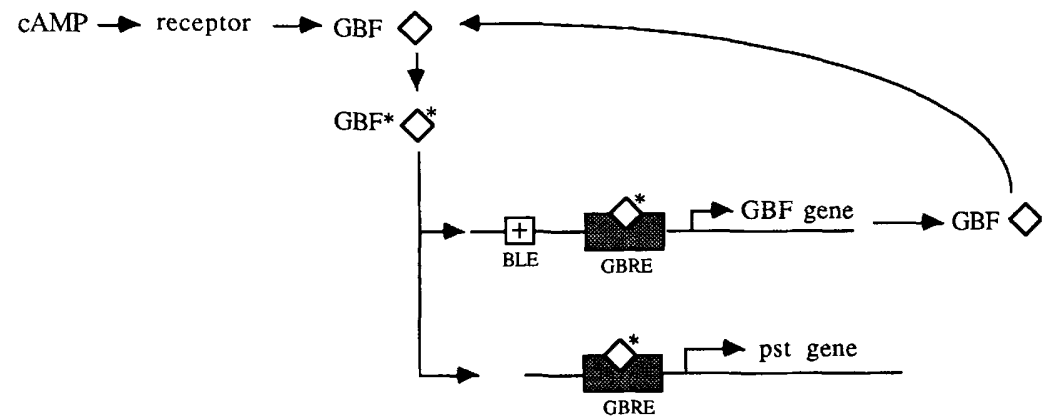

Figure 7. Models for prestalk gene regulation. All models are based on cAMP-activating gene expression via a cell-surface cAMP receptor and mediated through an intracellular signal transduction process (see introductory section). In model $\mathrm{I}$, an already present GBF is activated by a post-translational modification resulting in an increase in its binding affinity for the GBRE, thereby causing activation of prestalk gene expression. In model IIA and IIB, activation of the receptor results in the activation of transcription of GBF. In IIA, a cARF already present is activated, which causes an increase in the rate of transcription of the gene for the GBF and thereby produces increased GBF synthesis. The gene for GBF exhibits low constitutive expression that is driven by the basal element (BLE) and that accounts for the low level of GBF present in vegetative and 5-hr cells. cARF is activated, presumably by a post-translational modification. A higher level of expression of the GBF results in the activation of prestalk genes. The model shows that an activation of GBF prior to its binding to the regulatory element accounts for the observed increase in binding activity in the presence of protein synthesis inhibitors. In model IIB, activation of the receptor by cAMP results in the activation of low levels of GBF already present in the cells. The low levels of GBF result from the expression of the GBF gene through the BLE. Activation of the preexisting, yet low, levels of GBF results in an increased binding to the upstream regulatory region of the GBF gene, which ultimately results in an increase in expression of GBF. This feeds back and activates expression of the GBF gene. Higher levels of GBF can now activate GBRE elements on downstream prestalk genes. An additional model (data not shown) implies that activation of the cAMP receptor results in an increase in expression of a modifying enzyme that acts on GBF and increases its affinity for the GBRE. Although this model is as consistent with our data as are models IIA and IIB, we feel that transcription and expression of a modifying factor in response to cAMP decreases the subsequent flexibility in the system and in our view is a more circuitous approach to activating prestalk gene expression.

of these cells. In Dictyostelium, a severalfold modulating effect of cAMP, as seen in mammalian cells, would be inappropriate for this developmental task. Thus, if environmental or other factors resulted in conditions inappropriate for a continuation of differentia- tion, a decrease in the level of cAMP synthesis would result in the turning off of GBF synthesis, and development would be delayed at that point until favorable conditions again arose. Purification of the factor and production of antibodies as well as subsequent cloning of the 
gene for GBF will allow a further molecular analysis of the mechanisms that control prestalk gene expression in Dictyostelium.

\section{Materials and methods \\ Dictyostelium growth and development of Dictyostelium strains}

The Dictyostelium discoideum axenic strain, $\mathrm{KAx}-3$, was grown in HL-5 medium. For development, the cells were harvested by centrifugation, washed, and plated either on filters for the isolation of RNA or on nonnutrient agar for the harvesting of large quantities of cells for developmental time courses. All procedures have been described previously (Firtel and Lodish 1973; Mann and Firtel 1987).

\section{Molecular techniques}

All cloning procedures were done by use of standard techniques. RNA and DNA from Dictyostelium strains were isolated as described previously (Nellen et al. 1987) (see figure legends for descriptions of the vectors used in specific experiments).

The pst-cathepsin (CP2) minigene and minigene $\Delta 30$ were described previously (Pears and Williams 1987, 1988).

\section{Nuclear extracts}

Nuclei were isolated from vegetative Dictyostelium KAx-3 cells that were grown in shaking suspensions of HL-5 medium and from cells at various stages of development. Multicellular development of Dictyostelium cells was performed by plating at high density $\left(6 \times 10^{6}\right.$ cells $\left./ \mathrm{cm}^{2}\right)$ on nonnutrient $1.2 \%$ agar plates [12 mM Na-phosphate (pH 6.1), $2 \mathrm{mM} \mathrm{MgSO}_{4}, 0.2 \mathrm{mM}$ $\mathrm{CaCl}_{2}$, and $250 \mu \mathrm{mg} / \mathrm{ml}$ streptomycin]. Developmental induction of unaggregated Dictyostelium cells was as described previously (Mehdy et al. 1983). Cell disruption was performed by the passage of the cell suspension at $\sim 2 \times 10^{8}$ cells $/ \mathrm{ml}$ of lysis buffer through $5-\mu \mathrm{m}$ polycarbonate filters. [Lysis buffer: $50 \mathrm{~mm}$ HEPES ( $\mathrm{pH} 7.5$ ), $40 \mathrm{~mm} \mathrm{MgCl}_{2}, 20 \mathrm{~mm} \mathrm{KCl}, 2 \mathrm{~mm}$ DTT, $5 \%$ sucrose, $0.15 \mathrm{~mm}$ spermine, $0.5 \mathrm{~mm}$ spermidine, and $10 \%$ Percoll.] Nuclei were concentrated, resuspended in buffer $Z$, and salt-extracted with a final concentration of $0.35 \mathrm{M} \mathrm{NH}_{4}\left(\mathrm{SO}_{4}\right)_{2}$, and the salt-extracted material was cleared by $40,000-\mathrm{rpm}$ centrifugation at $4^{\circ} \mathrm{C}$ for $2 \mathrm{hr}$ (Beckman Ti50). The supernatant was concentrated by a $60 \%$ ammonium sulfate precipitation; the resuspended and dialyzed pellet constituted the crude nuclear extract. Protease inhibitors (Theibert et al. 1984) were present throughout the nuclear extract preparation. Heat treatment of the nuclear extracts was done at $80^{\circ} \mathrm{C}$ for $2 \mathrm{~min}$ at a protein concentration of $1 \mathrm{mg} / \mathrm{ml}$ in the presence of $0.1 \mathrm{mg} / \mathrm{ml}$ bovine serum albumin (BSA). Protein concentration was determined by the Bradford method using Bio-Rad reagent. The extract buffer $\mathrm{Z}$ has the following composition: $25 \mathrm{mM}$ HEPES (pH 7.5), 12.5 $\mathrm{mM} \mathrm{MgCl}, 100 \mathrm{~mm} \mathrm{KCl}, 0.1 \mathrm{~mm}$ EDTA, $1 \mathrm{~mm} \mathrm{DTT}, 20 \%$ glycerol, and $0.1 \%$ Triton $\mathrm{X}-100$.

\section{Transformation of Dictyostelium}

DNA-mediated transformation of Dictyostelium $\mathrm{KAx}-3$ cells was done by electroporation with conditions as described previously (Howard et al. 1988).

Transformants were selected on plates by growth in HL-5 supplemented with $10 \mu \mathrm{g} / \mathrm{ml} \mathrm{G418}$ and grown subsequently in shaking culture in the presence of G418. Total cellular DNA was isolated, and the copy number of transformed plasmid DNA was determined by Southern blot analysis. Expression of minigene mRNA was evaluated relative to endogenous pst-cathepsin gene expression by electrophoresis of total cellular RNA on $1.2 \%$ formaldehyde-agarose gels followed by Northern blotting. Northern and Southern blot analyses were performed as described previously (Mehdy et al. 1988) by use of a $1.2-\mathrm{kb} E c o \mathrm{RV}-K p n I$ genomic fragment of the pst-cathepsin (CP2) gene $(-742$ to +386$)$ prepared as a randomly primed probe.

\section{Cloning of oligonucleotides for in vivo analysis}

Self-annealed and ligated synthetic CP2 36-mer oligonucleotides were cloned into the BamHI site of the transformation vector CP2 430 (described in Pears and Williams 1987). The 43mers were cloned after the BamHI site was changed to a HindIII site (CP2 43-mer oligonucleotides have HindIII ends). The transformation vector conferred G418 resistance to transformed cells and carried a pst-cathepsin $(\mathrm{CP} 2)$ minigene from which an intragenic KpnI fragment had been deleted. The resulting minigene mRNA was $\sim 500$ nucleotides shorter than the endogenous mRNA (Pears et al. 1985, 1987; Datta et al. 1986; Datta and Firtel 1987). A minigene transformation vector that contained wild-type upstream sequence was used as a control.

\section{DNA binding assays}

DNA-protein complex formation was analyzed by gel mobility shift (Fried and Crothers 1981; Garner and Revzin 1981). The probe consisted of a PstI-Asp 718 linear fragment of cloned CP2 oligonucleotide (see Fig. 8 below) labeled with [32P]ATP and polynucleotide kinase. Probe $(\sim 0.2 \mathrm{ng}$ of DNA) and extract were mixed in the presence of nonspecific competitor poly[d!lC)] at a 500-fold weight excess and specific competitor as indicated in the figures, incubated at room temperature for $15 \mathrm{~min}$, and electrophoresed on $4 \%$ native polyacrylamide gels [ $45 \mathrm{~mm}$ Tris-borate ( $\mathrm{pH} 7.5)$ ]. [Binding buffer: $10 \mathrm{mM}$ Tris- $\mathrm{HCl}(\mathrm{pH} 7.5)$, $10 \mathrm{mM} \mathrm{MgCl}_{2}, 80 \mathrm{~mm} \mathrm{KCl}, 0.1 \mathrm{~mm}$ EDTA, 4\% glycerol, and $0.1 \%$ Triton X-100.]

\section{Methylation-interference analysis}

A single-copy clone of the CP2 43-mer was used in this assay. A uniquely end-labeled probe was obtained by $S p h I$ digestion of a kinased $P_{s t I}-A s p 718$ fragment. Desalted and lyophilized DNA $(\sim 10 \mathrm{ng})$ was methylated partially at $20^{\circ} \mathrm{C}$ in $50 \mathrm{~mm} \mathrm{Na-caco-}$ dylate (pH 7.1), $1 \mathrm{mM}$ EDTA, $10 \mathrm{mM} \mathrm{MgCl}_{2}$ with $1 \mu \mathrm{LMS}$ for 15-90 seconds (Sturm et al. 1987).
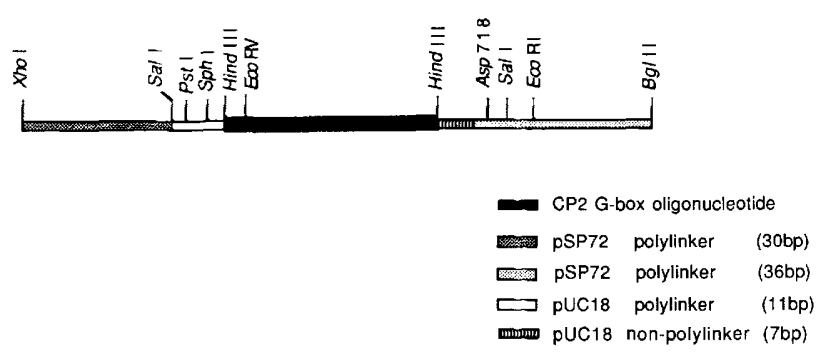

Figure 8. Structure of cloned CP2 43-mer used as probes. pSP72 is from Promega Biotech. 
The partially methylated probe was incubated with heattreated extract and separated into free and protein-complexed form by gel-mobility shift electrophoresis, and localized subsequently by autoradiography of wet gels. The DNA was eluted onto NA45 paper, cleaved with $10 \%$ piperidine, and analyzed on $10 \%$ urea-acrylamide gels.

\section{Acknowledgments}

We would like to thank Jeff Williams for helpful discussions and for making available a number of plasmids that have assisted our work. A.L.H. was supported in part by a predoctoral fellowship from the Danish Natural Sciences Research Council. This work was supported by research grant USPHS GM-24279 to R.A.F.

\section{References}

Datta, S. and R.A. Firtel. 1987. Identification of the sequences controlling cyclic AMP regulation and cell-type-specific expression of a prestalk-specific gene in Dictyostelium discoideum. Mol. Cell. Biol. 7: 149-159.

- 1988. An 80-bp cis-acting regulatory region controls cAMP and developmental regulation of a prestalk gene in Dictyostelium. Genes Dev. 2: 294-304.

Datta, S., R.H. Gomer, and R.A. Firtel. 1986. Spatial and temporal regulation of a foreign gene by a prestalk-specific promoter in transformed Dictyostelium discoideum. Mol. Cell. Biol. 6: 811-820.

Datta, S., S.K.O. Mann, A. Hjorth, R. Gomer, P. Howard, D. Armstrong, C. Reymond, C. Silan, and R.A. Firtel. 1987. cAMP-regulated gene expression during Dictyostelium development is mediated by the cell-surface cAMP receptor. In Genetic regulation of development, pp. 33-61. Alan R. Liss, Inc., New York.

Driscoll, D. and J.G. Williams. 1987. Two divergently transcribed genes of Dictyostelium discoideum are cyclic AMPinducible and coregulated during development. Mol. Cell. Biol. 7: 4482-4489.

Firtel, R.A. and H.F. Lodish. 1973. A small nuclear precursor of messenger RNA in the cellular slime mold Dictyostelium discoideum. J. Mol. Biol. 79: 295-314.

Fried, M.G. and D.M. Crothers. 1981. Equilibria and kinetics of lac repressor-operator interactions by polyacrylamide gel electrophoresis. Nucleic Acids Res. 9: 6505-6525.

Garner, M.M. and A. Revzin. 1981. A gel electrophoresis method of quantifying the binding of proteins to specific DNA regions: Application to components of the E. coli lactose operon regulatory system. Nucleic Acids Res. 9: $3047-$ 3060.

Gomer, R.H., S. Datta, M. Mehdy, T. Crowley, A. Sivertsen, W. Nellen, C. Reymond, S. Mann, and R.A. Firtel. 1985. Regulation of cell-type-specific gene expression in Dictyostelium. Cold Spring Harbor Symp. Quant. Biol. 50: 801-812.

Gomer, R.H., D. Armstrong, B.H. Leichtling, and R.A. Firtel. 1986a. cAMP induction of prespore and prestalk gene expression in Dictyostelium is mediated by the cell-surface cAMP receptor. Proc. Natl. Acad. Sci. 83: 8624-8628.

Gomer, R.H., S. Datta, and R.A. Firtel. 1986b. Cellular and subcellular distribution of a cAMP-regulated prestalk protein and prespore protein in Dictyostelium discoideum: A study on the ontogeny of prestalk and prespore cells. J. Cell Biol. 103: $1999-2015$.

Haribabu, B. and R.P. Dottin. 1986. Pharmacological character- ization of cyclic AMP receptors mediating gene regulation in Dictyostelium discoideum. Mol. Cell. Biol. 6: 24022408.

Howard, P.K., K.G. Ahern, and R.A. Firtel. 1988. Establishment of a transient expression system for Dictyostelium discoideum. Nucleic Acids Res. 16: 2613-2623.

Janssens, P.M.W. and P.J.M. van Haastert. 1987. Molecular basis of transmembrane signal transduction in Dictyostelium discoideum. Microbiol. Rev. 51: 396-418.

Johnson, P.F., W.H. Landschulz, B.J. Graves, and S.L. McKnight. 1987. Identification of rat liver nuclear protein that binds to the enhancer core element of three animal viruses. Genes Dev. 1: 133-146.

Klein, P., T.J. Sun, C.L. Saxe, A.R. Kimmel, and P.N. Devreotes. 1988. A chemoattractant receptor controls development in Dictyostelium discoideum. 241: 1467-1472.

Kumagai, A., S.K.O. Mann, M. Pupillo, P.N. Devreotes, and R.A. Firtel. 1988. A molecular analysis of $G$ proteins and control of early gene expression by the cell surface cAMP receptor in Dictyostelium. Cold Spring Harbor Symp. Quant. Biol. 53: 675-685.

Kumagai, A., M. Pupillo, R. Gunderson, R. Miake-Lye, P.N Devreotes, and R.A. Firtel. 1989. Regulation and function of $\mathrm{G}_{\alpha}$ protein subunits in Dictyostelium. Cell (in press).

Landshulz, W.H., P.F. Johnson, E.Y. Adashi, B.J. Graves, and S.L. McKnight. 1988. Isolation of a recombinant copy of the gene encoding C/EBP. Genes Dev. 2: 786-800.

Loomis, W.F. (ed.) 1975. Dictyostelium discoideum, A developmental system. Academic Press, New York.

Loomis, W.F. (ed.). 1982. The development of Dictyostelium discoideum. Academic Press, New York.

Mann, S.K.O. and R.A. Firtel. 1987. Cyclic AMP regulation of early gene expression in Dictyostelium discoideum: Mediation via the cell surface cyclic AMP receptor. Mol. Cell. Biol. 7: 458-469.

- 1989. A two-phase regulatory pathway controls cAMPreceptor mediated expression of early genes in Dictyostelium. Proc. Natl. Acad. Sci. 86: 1924-1928.

Mann, S.K.O., S. Datta, P. Howard, A. Hjorth, C. Reymond, C.M. Silan, and R.A. Firtel. 1987. Cyclic AMP regulation of gene expression during Dictyostelium development. In Molecular approaches to developmental biology, led. R.A. Firtel and E.H. Davidson), pp. 303-328. Alan R. Liss, New York.

Mann, S.K.O., C. Pinko, and R.A. Firtel. 1988. cAMP regulation of early gene expression in signal transduction mutants of Dictyostelium. Dev. Biol. 130: 294-303.

Mehdy, M.C. and R.A. Firtel. 1985. A secreted factor and cyclic AMP jointly regulate cell-type-specific gene expression in Dictyostelium discoideum. Mol. Cell. Biol. 5: 705-713.

Mehdy, M.C., D. Ratner, and R.A. Firtel. 1983. Induction and modulation of cell-type-specific gene expression in Dictyostelium. Cell 32: 761-771.

Mehdy, M.C., C.L. Saxe, and R.A. Firtel. 1984. The regulation of cell-type-specific genes in Dictyostelium. In Molecular biology of development (ed. E.H. Davidson and R.A. Firtel), pp. 293-308. Alan R. Liss, New York.

Nellen, W., C. Silan, U. Saur, and R.A. Firtel. 1986. Regulatory sequences in the promoter of the Dictyostelium Actin 6 gene. $E M B O$ I. 5: 3367-3372.

Nellen, W., S. Datta, C. Reymond, A. Sivertsen, S. Mann, T. Crowley, and R.A. Firtel. 1987. Molecular biology in Dictyostelium: Tools and applications. Methods Cell Biol. 28: $67-100$

Oyama, M. and D.D. Blumberg. 1986. Interaction of cAMP with the cell-surface receptor induces cell-type-specific mRNA 
accumulation in Dictyostelium discoideum. Proc. Natl. Acad. Sci. 83: 4819-4823.

Pears, C.J., H.M. Mahbubani, and J.G. Williams. 1985. Characterization of two highly diverged but developmentally coregulated cysteine proteinase genes in Dictyostelium discoideum. Nucleic Acids Res. 13: 8853-8866.

Pears, C.J. and J.G. Williams. 1987. Identification of a DNA sequence element required for efficient expression of a developmentally regulated and cAMP-inducible gene of Dictyostelium discoideum. EMBO f. 6: 195-200.

1988. Multiple copies of a G-rich element upstream of a cAMP-inducible Dictyostelium gene are necessary but not sufficient for efficient gene expression. Nucleic Acids Res. 16: $8467-8486$.

Pfeifer, K., T. Prezant, and L. Guarente. 1987. Yeast HAPI activator binds to two upstream activation sites of different sequences. Cell 49: 19-27.

Poole, S.J. and R.A. Firtel. 1984. Conserved structural features are found upstream from the three coordinately regulated Discoidin I genes of Dictyostelium discoideum. I. Mol. Biol. 172: 203-220.

Pupillo, M., A. Kumagai, G. Pitt, R.A. Firtel, and P.N. Deverotes. 1989. Proc. Natl. Acad. Sci. (in press).

Reymond, C.D., R.H. Gomer, M.C. Mehdy, and R.A. Firtel. 1984. Developmental regulation of a Dictyostelium gene encoding a protein homologous to mammalian ras protein. Cell 39: 141-148.

Reymond, C.D., W. Nellen, and R.A. Firtel. 1985. Regulated expression of ras gene constructs in Dictyostelium transformants. Proc. Natl. Acad. Sci. 82: 7005-7009.

Schaap, P. and R. van Driel, 1985. Induction of post-aggregative differentiation in Dictyostelium discoideum by cAMP. Exp. Cell Res. 159: 388-398.

Schaap, P., M. van Lookeren Campagne, R. van Driel, W. Spek, P.J.M. van Haastert, and J. Pinas. 1986. Postaggregative differentiation induction by cyclic AMP in Dictyostelium: Intracellular transduction pathway and requirement for additional stimuli. Dev. Biol. 118: 52-63.

Sturm, R., T. Baumruker, B.R. Franza, and W. Herr. 1987. A $100-\mathrm{kd}$ HeLa cell octamer binding protein (OBP100) interacts differently with two separate octamer-related sequences within the SV40 enhancer. Genes Dev. 1: 11471160.

Theibert, A., P. Klein, and P. Devreotes. 1984. Specific photoaffinity labelling of cAMP surface receptor in Dictyostelium discoideum. J. Biol. Chem. 259: 2318-12321.

Williams, J.G.. 1988. The role of diffusible molecules in regulating the cellular differentiation of Dictyostelium discoideum. Development 103: 1-16.

Williams, J.G., A.S. Tsang, and H. Mahbubani. 1980. A change in the rate of transcription of a eukaryotic gene in response to cyclic AMP. Proc. Natl. Acad. Sci. 77: 7171-7175.

Williams, J.G., C.J. Pears, K.A. Jermyn, D.M. Driscoll, H. Mahbubani, and R.R. Kay. 1986. The control of gene expression during cellular differentiation of Dictyostelium discoideum. In Regulation of gene expression (ed. I. Booth and C. Higgens|, pp. 277-298. Cambridge University Press, Oxford.

Yamamoto, K.K., G.A. Gonzalez, W.H. Biggs III, and M.R. Montminy. 1988. Phosphorylation-induced binding and transcriptional efficacy of nuclear factor CREB. Nature 334: 494-498. 


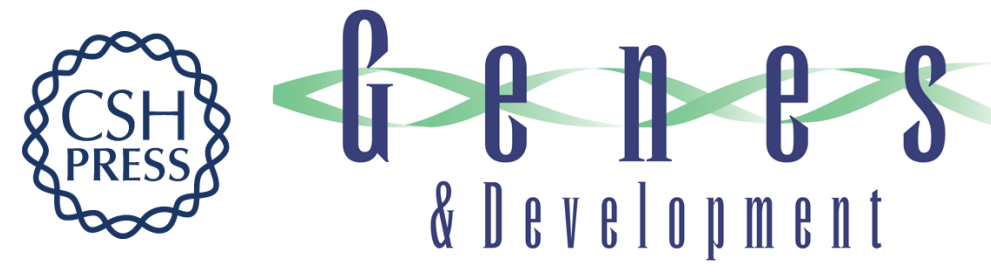

\section{A trans-acting factor required for CAMP-induced gene expression in Dictyostelium is regulated developmentally and induced by CAMP.}

A L Hjorth, N C Khanna and R A Firtel

Genes Dev. 1989, 3:

Access the most recent version at doi:10.1101/gad.3.6.747

References This article cites 38 articles, 19 of which can be accessed free at:

http://genesdev.cshlp.org/content/3/6/747.full.html\#ref-list-1

License

Email Alerting

Service

Receive free email alerts when new articles cite this article - sign up in the box at the top right corner of the article or click here.

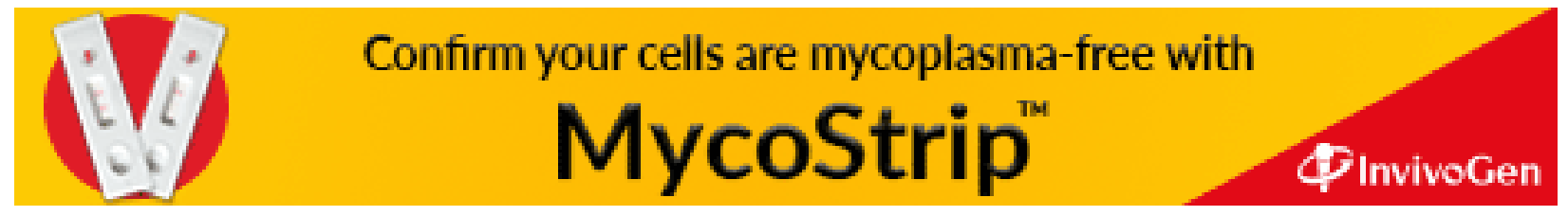

